\title{
Development of an anisotropic beam finite element for composite wind turbine blades in multibody system
}

Kim, Taeseong; Hansen, Anders Melchior; Branner, Kim

Published in:

Renewable Energy

Link to article, DOI:

10.1016/j.renene.2013.03.033

Publication date:

2013

Link back to DTU Orbit

Citation (APA):

Kim, T., Hansen, A. M., \& Branner, K. (2013). Development of an anisotropic beam finite element for composite wind turbine blades in multibody system. Renewable Energy, 59, 172-183.

https://doi.org/10.1016/j.renene.2013.03.033

\section{General rights}

Copyright and moral rights for the publications made accessible in the public portal are retained by the authors and/or other copyright owners and it is a condition of accessing publications that users recognise and abide by the legal requirements associated with these rights.

- Users may download and print one copy of any publication from the public portal for the purpose of private study or research.

- You may not further distribute the material or use it for any profit-making activity or commercial gain

- You may freely distribute the URL identifying the publication in the public portal

If you believe that this document breaches copyright please contact us providing details, and we will remove access to the work immediately and investigate your claim. 


\title{
Development of an Anisotropic Beam Finite Element for Composite Wind Turbine Blades in Multibody System
}

\author{
Taeseong Kim ${ }^{1}$, Anders M. Hansen ${ }^{2}$, and Kim Branner ${ }^{3}$ \\ Department of Wind Energy, Technical University of Denmark (DTU), Roskilde, Denmark
}

\begin{abstract}
In this paper a new anisotropic beam finite element for composite wind turbine blades is developed and implemented into the aeroelastic nonlinear multibody code, HAWC2, intended to be used to investigate if use of anisotropic material layups in wind turbine blades can be tailored for improved performance such as reduction of loads and/or increased power capture. The element stiffness and mass matrices are first derived based on pre-calculated anisotropic beam properties, and the beam element is subsequently put into a floating frame of reference to enable full rigid body displacement and rotation of the beam. This derivation provides the mass and stiffness properties and the fictitious forces needed for implementation into HAWC2. The implementation is subsequently validated by running three validation cases which all show good agreement with results obtained by other authors. Further, a parametric study is conducted in order to investigate if the given anisotropic effect of the composite blade, bend-twist coupling effect, is able to be examined by the developed beam element in a multibody system or not. Two different coupled examples of bend-twist coupling for the blade of a 5MW fictitious wind turbine are considered. The two cases differ in the amount of bend-twist coupling introduced into the blade so that they produce $0.3 \mathrm{deg}$ and $1 \mathrm{deg}$ twist at the blade tip (towards feather), respectively, for a $1 \mathrm{~m}$ flapwise tip deflection towards the tower. It is examined if the current structural model is able to capture the anisotropic effects in a multibody system.
\end{abstract}

\section{KEYWORDS}

Anisotropic beam element, multibody system, HAWC2, structural coupling, composite blade, wind turbine

\section{INTRODUCTION}

Wind turbine blades are getting larger and more flexible. It introduces higher nonlinear behavior of wind turbines. While nonlinear effects is a relatively new focus area in the wind turbine society, there have been many investigations in the helicopter society for decades. ${ }^{1,2}$ Friedmann et $\mathrm{al}^{3}{ }^{3}$ and Hodges et $\mathrm{al}^{4}{ }^{4}$ developed a nonlinear beam model including elastic flap-

\footnotetext{
${ }^{1}$ Senior Scientist, Department of Wind Energy, Building 114, Technical University of Denmark, Ris $\phi$ campus, 4000 Roskilde, Denmark. E-mail: tkim@dtu.dk

${ }^{2}$ Senior Development Engineer, Department of Wind Energy, Building 114, Technical University of Denmark, Ris $\phi$ campus, 4000 Roskilde, Denmark. E-mail: anmh@dtu.dk

${ }^{3}$ Senior Scientist, Department of Wind Energy, Building 114, Technical University of Denmark, Risø campus, 4000 Roskilde, Denmark. E-mail: kibr@dtu.dk
} 
edge dynamics of a rotating beam. The analytical nonlinear beam equation of motion, coupling bending and torsion, becomes very long and complicated. Therefore, ordering schemes are introduced..$^{5-9}$ However, the derivation of the equation of motion with an ordering scheme is not consistent. It is very dependent on who conducts the analyses and which nonlinear effects produced by higher order terms are neglected. Therefore, an exact beam theory which does not rely on an ordering scheme was introduced by Hodges. ${ }^{10}$ The kinematics of this theory are exact. Simo $^{11}$, Simo et al. ${ }^{12}$, and Hodges ${ }^{13}$ introduced a mixed formulation which is in first order form. The mentioned advanced beam theories focus on improving the kinematic representation of the beam motion. However, it is still assumed that beams are from homogeneous, isotropic materials, and linearly elastic. This does not fit with a composite beam model which must consider anisotropic material effects and warping effects. Bauchau expanded Euler-Bernoulli beam theory including a transverse shear and a warping displacement. ${ }^{14}$ He extended the beam theory to orthotropic materials. ${ }^{15,16}$ A finite element method was introduced to analyze arbitrary cross-section geometries including open sections by Kosmatka. ${ }^{17,18}$ A two dimensional finite element method which is able to compute generalized warping functions and cross-sectional properties for straight and untwiswted beams with arbitrary cross-sectional geometries was developed by Giavotto et al. ${ }^{19}$ And then Borri et al. ${ }^{20}$ extended the beam model to curved and twisted beams. Hodges and his colleagues ${ }^{21-27}$ introduced a finite element based cross-section analysis method using the variational asymptotic method ${ }^{28}$ to reduce a general three-dimensional nonlinear anisotropic elasticity problem into a two-dimensional linear cross-sectional analysis and a one-dimensional nonlinear beam analysis. Three-dimensional warping functions are asymptotically computed by two-dimensional cross-section analysis. The constitutive model for the one-dimensional nonlinear beam analysis is obtained as well. This approach is able to compute any initially twisted and curved, inhomogeneous, anisotropic beam with arbitrary crosssectional geometries.

Wind turbine blades must be designed to resist the fatigue loads from normal operation and the extreme loads cases caused by extreme conditions. Sudden wind gusts are often too quick for the active pitch control system to react on and may shorten the fatigue life substantially. This problem may be overcome by an aeroelastic tailoring of the blades. By using the anisotropic properties of composite materials, bend-twist and other couplings can be built into the blades. The bend-twist coupling causes the feathering blade to twist under the bending load and can be designed in a manner where the angle of attack decreases with increasing bending load.

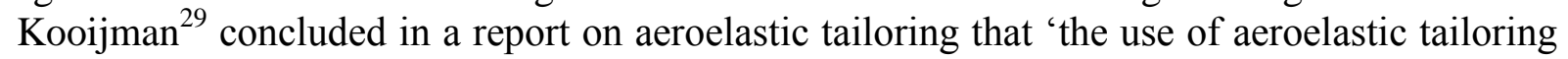
of the Fiber Reinforced Plastics to control limited torsional deformation is a promising way to improve rotor blade design'. He found that building a bend-twist coupling into the blade gives the potential for a few per cent of energy yield improvement for constant-speed pitch-controlled turbines and improves starting torque by 10 per cent. For a constant-speed pitch-controlled rotor, it is found that the largest power production is obtained with the inboard span twisting to feather and the outboard 60 per cent of the span twisting towards stall.

Middleton et $a l .{ }^{30}$ and Infield et $a l .{ }^{31}$ designed, analyzed, fabricated and tested an axial-twist coupled blade developed to control the rotor in a runaway scenario. Their composite blade was fabricated using a helical lay-up with layers of glass and carbon fibers. Measured twist coupling agreed well with the predictions.

At Technical University of Denmark (DTU) an $8 m$ section from a $23 m$ blade from Vestas Wind Systems A/S has been tested for both static and dynamic manner. The original blade section was tested and then modified with four layers of UD1200 (unidirectional glass fiber, 
$1200 \mathrm{~g} / \mathrm{m}^{2}$ ) which were laminated on the pressure and suction side of the blade with an angle of 25 degrees to the blade axis to create a measurable flapwise bend-twist coupling. The initial test results and comparison with numerical analyses show that the original blade section has very small couplings but that these can be introduced easily by adding angled unidirectional layers. ${ }^{32,33}$ In Luczak et $a .^{34}$ the bend-twist coupling was also investigated by means of experimental and numerical modal analysis. The research focused on the presence of the bendtwist coupling in the mode shapes of the blade section and the influence of an additional mass and stiffness introduced by the extra layers. In both the static and dynamic test campaigns, the comparison of original and modified blade properties clearly show the presence of the bend-twist coupling. However, it was found to be quite challenging to get a reliable prediction of the bendtwist coupling from the modal analyses. The measured bend-twist coupling from the static tests agree very well with numerical predictions.

Research at the National Renewable Energy Laboratory (NREL) in USA have focused on the application of blades with bend-twist coupling on constant-speed turbines. Results indicate that energy capture can be increased significantly if the bend-twist coupled blades are made to twist towards stall while increasing the rotor diameter to maintain the maximum power at its design value. ${ }^{35}$ However, subsequent simulations with the rotor in turbulent winds showed substantial increases in fatigue damage. Moreover, for a range of wind speeds in the stall regime stall flutter was observed. ${ }^{36}$ However, when the blades twist towards feather it was found that fatigue damage is reduced by approximately a factor of two and stall flutter is not observed. ${ }^{37}$

In Lobitz \& Veers ${ }^{38}$ load reduction with bend-twist coupled blades were studied employing modern control strategies. All this work takes only the bend-twist coupling into account and is based on a simplified plane Bernoulli-Euler type of approach. Important steps towards using blade couplings for load reductions have therefore been taken by Lobitz, Veers and their colleagues ${ }^{35-39}$ but the full potential of passive control of wind turbine blades is still to be explored.

The mentioned investigations focused on understanding blade dynamic effect by considering composite tailoring effects. However, a wind turbine has multiple components such as rotor, hub, shaft, generator, gearbox, nacelle, tower, etc. All parts in a turbine interact with each other. Therefore, in order to investigate the overall turbine dynamic responses resulting from a blade structural coupling effect, an entire turbine including rotor, shaft, nacelle, tower, etc., must be considered with an integrated model - not only the blade. In other words, aeroelastic computations with an entire turbine configuration are necessary.

HAWC2 is the in-house aeroelastic nonlinear multibody code intended for calculating wind turbine response in time domain developed by DTU Wind Energy. ${ }^{40,41}$ In the present version of HAWC2 the structural model of the wind turbine is modeled by Timoshenko beam elements which only include the classical Timoshenko beam properties, i.e. bending stiffness, shear stiffness, etc. A single classical, linear Timoshenko or Bernoulli-Euler beam model cannot capture the nonlinear behavior of a large wind turbine blade primarily due to the violation of the small rotation assumption of the beam cross-sections which is inherent in such linear models. However, structures in HAWC2 can be divided into several substructures due to the multibody formulation adapted. ${ }^{42}$ Each substructure has its own coordinate system and when the coordinate system is moved in space internal inertia loads are calculated. Therefore, structural nonlinear effects such as large rotations and translations are able to be captured although the formulation is linear inside each substructure. ${ }^{43}$ The multibody approach provides another benefit as the whole turbine configuration is modeled by an assembly of bodies connected with constraint equations 
such as a rigid coupling, a bearing coupling, a prescribed fixed bearing angle, etc. This makes it possible to simulate an entire turbine system response. However, the current beam elements cannot be used to investigate the aforementioned coupling effects of anisotropic composite materials because the beam elements currently used assume isotropic material. The purpose of this paper is to develop a new anisotropic beam finite element in multibody system and implement it into the structural part of HAWC2.

\section{METHODS}

In this section the steps to include the new anisotropic beam element into HAWC2 are described. The derivation of element stiffness and mass matrices are derived in section 2.1. This derivation indirectly provides the shape functions of the element which are used in section 2.2 to derive kinematic formulation of the element in a multibody floating frame of reference. Finally, in section 2.3, the complete mass matrix for the anisotropic element in a floating frame of reference is given along with the fictitious forces. The coordinate system used in this study is illustrated in Figure 1.

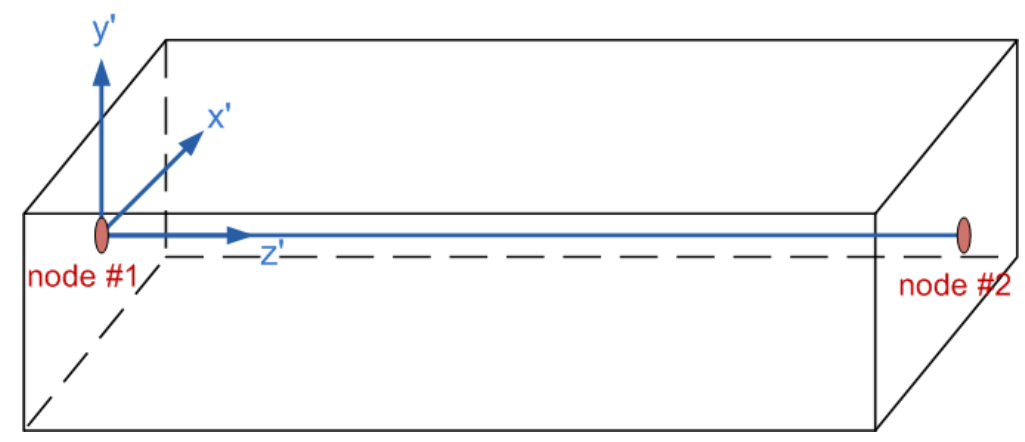

Figure 1. A sketch of the coordinate system in HAWC2

\subsection{An anisotropic beam finite element}

The elastic energy and the kinetic energy of a beam are considered for deriving a stiffness and a mass matrix of a beam, respectively. The stiffness matrix is derived by assuming that the beam states (deflections and rotations) can be described by polynomials of arbitrarily high order. This approach introduces a high number of degrees of freedom for the states and that high number is subsequently condensed by minimizing the elastic energy of the entire beam with constraints of prescribed states at the beam ends. This approach indirectly results in shape functions which are equal to the static deflection state for a beam with prescribed end conditions.

Equation (1) shows the elastic energy of the beam.

$$
2 U=\int_{0}^{L}\left(\varepsilon^{T} S \varepsilon\right) d z^{\prime}
$$

where $\varepsilon$ is the beam strain vector, and $S$ is the cross-sectional stiffness matrix defined by a diagonal matrix into the current HAWC2. If the reference coordinate system of the beam is 
located and aligned with the main bending axes and coinciding with the elastic center and the shear center, $S$ becomes a diagonal matrix,

$$
S=\left[\begin{array}{cccccc}
k_{x} G A & 0 & 0 & 0 & 0 & 0 \\
0 & k_{y} G A & 0 & 0 & 0 & 0 \\
0 & 0 & E A & 0 & 0 & 0 \\
0 & 0 & 0 & E I_{x} & 0 & 0 \\
0 & 0 & 0 & 0 & E I_{y} & 0 \\
0 & 0 & 0 & 0 & 0 & G J
\end{array}\right]
$$

The classical beam properties are located in the diagonal. For the general anisotropic case, however, the $S$ matrix becomes a full symmetric matrix in which the off-diagonal terms express the couplings introduced by the material layup. It is beyond the scope of this paper to go into the details of how the $S$ matrix is calculated - it is just assumed that $S$ has already been computed by cross-section analysis tools such as $\mathrm{BECAS}^{44}$ or $\mathrm{VABS}^{23-27}$.

In equation (1) the generalized strains of the Timoshenko beam, $\varepsilon$, are expressed as

$$
\begin{aligned}
& \{\varepsilon\}^{T}=\left\{\begin{array}{llllll}
\varepsilon_{x^{\prime}}, & \varepsilon_{y^{\prime}}, & \varepsilon_{z^{\prime}}, & \kappa_{x^{\prime}}, & \kappa_{y^{\prime}}, & \kappa_{z^{\prime}}
\end{array}\right\} \\
& =\left\{u_{x^{\prime}}{ }^{\prime}-\theta_{y^{\prime}}, \quad-u_{y^{\prime}}{ }^{\prime}-\theta_{x^{\prime}}, \quad u_{z^{\prime}}{ }^{\prime}, \quad \theta_{x^{\prime}}^{\prime}, \quad \theta_{y^{\prime}}^{\prime}, \quad \theta_{z^{\prime}}{ }^{\prime}\right\}
\end{aligned}
$$

The displacements and rotations can be expressed by an interpolating polynomial in terms of generalized degrees of freedom as follows

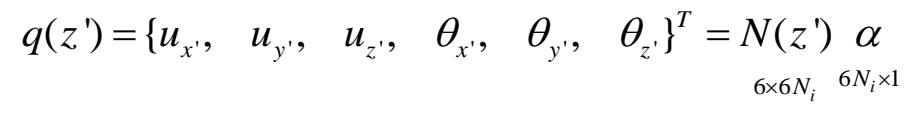

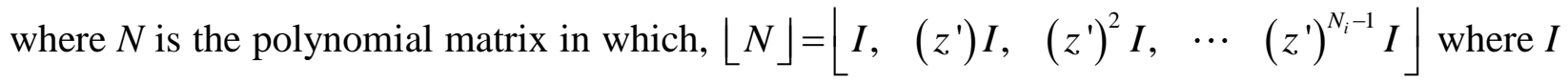
is a 6 by 6 identity matrix, $\alpha$ is the generalized degrees of freedom, and $N_{i}$ is the highest power in the polynomial +1 .

From the equations (3) and (4) the generalized strain can be expanded in terms of a straindisplacement matrix and generalized degrees of freedom as follows

$$
\varepsilon=B\left(z^{\prime}\right) \alpha
$$

where $B$ is the strain-displacement matrix which includes a polynomial matrix and its derivative terms as follows

$$
B\left(z^{\prime}\right)=B_{0} N\left(z^{\prime}\right)+B_{1} N^{\prime}\left(z^{\prime}\right)
$$

In equation (6) $B_{0}$ and $B_{1}$ can be illustrated as follows 


$$
B_{0}=\left[\begin{array}{cccccc}
0 & 0 & 0 & 0 & -1 & 0 \\
0 & 0 & 0 & -1 & 0 & 0 \\
0 & 0 & 0 & 0 & 0 & 0 \\
0 & 0 & 0 & 0 & 0 & 0 \\
0 & 0 & 0 & 0 & 0 & 0 \\
0 & 0 & 0 & 0 & 0 & 0
\end{array}\right], B_{1}=\left[\begin{array}{cccccc}
1 & 0 & 0 & 0 & 0 & 0 \\
0 & -1 & 0 & 0 & 0 & 0 \\
0 & 0 & 1 & 0 & 0 & 0 \\
0 & 0 & 0 & 1 & 0 & 0 \\
0 & 0 & 0 & 0 & 1 & 0 \\
0 & 0 & 0 & 0 & 0 & 1
\end{array}\right]
$$

By substituting equation (5) into equation (1), the elastic energy of the beam can be illustrated as follows

$$
2 U=\alpha^{T} \underbrace{\int_{0}^{L}\left(B^{T} S B\right) d z^{\prime}}_{D} \alpha
$$

In order to find $\alpha$ in equation (8) we first substitute part of $\alpha\left(\alpha_{1}\right)$ by the nodal degrees of freedom $(d)$, and then find the remainder of $\alpha\left(\alpha_{2}\right)$ by minimizing the elastic energy with respect to $\alpha_{2}$. By applying boundary conditions at each end of the beam the nodal degrees of freedom are obtained as follows

$$
\begin{aligned}
& d=N_{d} \quad \alpha \\
& \because 2 \times 1 \\
& \because\left\{\begin{array}{l}
d_{1} \\
d_{2}
\end{array}\right\}=\left[\begin{array}{l}
N(0) \\
N(L)
\end{array}\right] \alpha=\left[\begin{array}{l|l}
N_{1} \mid N_{2}
\end{array}\right]\left\{\begin{array}{l}
\alpha_{1} \\
\alpha_{2}
\end{array}\right\}
\end{aligned}
$$

where $N_{1}$ and $N_{2}$ become

$$
\underset{12 \times 12}{N_{1}}=\left[\begin{array}{c|c}
I & 0 \\
I & L I
\end{array}\right], \underset{12 \times\left(6 N_{i}-12\right)}{\underset{N_{2}}{I}}=\left[\begin{array}{c|c|c|c}
0 & 0 & \cdots & 0 \\
L^{2} I & L^{3} I & \cdots & L^{N_{i}-1} I
\end{array}\right]
$$

where $L$ is the length of the considered beam element.

From equations (9) and (10) $\alpha$ and $\alpha_{1}$ can be rewritten as

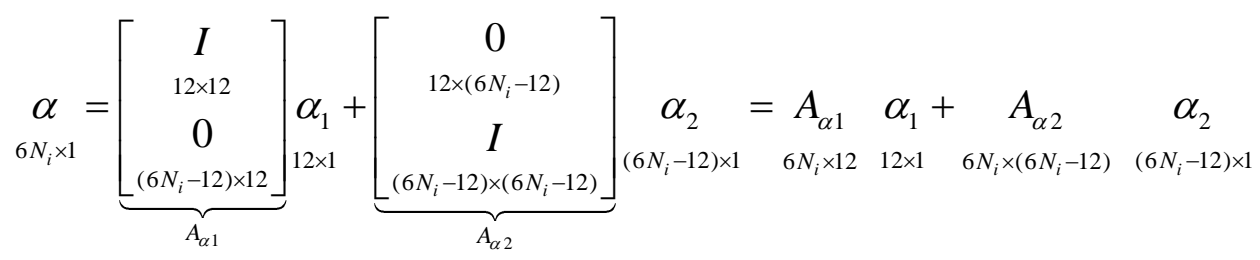

$$
\begin{aligned}
& \alpha_{1}=N_{1}^{-1}\left(d-N_{2} \alpha_{2}\right)
\end{aligned}
$$

By implementing equation (12) into equation (11) $\alpha$ can be expressed as follows 


$$
\begin{aligned}
\underset{6 N_{i} \times 1}{\alpha} & =\underbrace{A_{\alpha 1} N_{1}^{-1}}_{Y_{1}} d+\underbrace{\left(A_{\alpha 2}-A_{\alpha 1} N_{1}^{-1} N_{2}\right)}_{Y_{2}} \alpha_{2} \\
& =\underset{\substack{Y_{1} \\
6 N_{i} \times 12}}{Y_{12 \times 1}}+\underset{6 N_{i} \times\left(6 N_{i}-12\right)\left(6 N_{i}-12\right) \times 1}{Y_{2}} \alpha_{2}
\end{aligned}
$$

To compute the remainder of $\alpha$, the total elastic energy minimization approach in terms of $\alpha_{2}, \frac{d U}{d \alpha_{2}}=0$, is considered. From equations (8) and (13), the total elastic energy of the beam is obtained as follows

$$
U=\frac{1}{2} \underbrace{\left(d^{T} Y_{1}^{T}+\alpha_{2}{ }^{T} Y_{2}{ }^{T}\right)}_{\alpha^{T}} D \underbrace{\left(Y_{1} d+Y_{2} \alpha_{2}\right)}_{\alpha}
$$

Resulting from the total energy minimization, the $\alpha_{2}$ vector is obtained as follows

$$
\begin{aligned}
& \frac{d U}{d \alpha_{2}}=0 \\
& \therefore \underbrace{\left\{Y_{2}^{T} D Y_{1}\right\}}_{P} d=\underbrace{-\left\{Y_{2}^{T} D Y_{2}\right\}}_{Q} \alpha_{2} \\
& \Rightarrow \alpha_{2}=\underset{\left(6 N_{i}-12\right) \times\left(6 N_{i}-12\right)}{Q^{-1}} \underset{\left(6 N_{i}-12\right) \times 12}{P} \quad \begin{array}{cc}
12 \times 1
\end{array}
\end{aligned}
$$

By substituting equation (15) into equation (13), the $\alpha$ vector as a function of the nodal degrees of freedom is represented as follows

$$
\begin{aligned}
\alpha & =Y_{1} d+Y_{2} Q^{-1} P d=\left(Y_{1}+Y_{2} Q^{-1} P\right) d \\
& =\underset{\substack{\alpha \\
6 N_{i} \times 12}}{N_{\alpha}} d
\end{aligned}
$$

Finally, the elastic energy of the beam is obtained in terms of nodal degrees of freedom by substituting equation (16) into equation (8) as follows

$$
\begin{aligned}
U & =\frac{1}{2} d^{T} N_{\alpha}{ }^{T}\left[\int_{0}^{L}\left(B^{T} S B\right) d z^{\prime}\right] N_{\alpha} d \\
& =\frac{1}{2} d^{T} K d
\end{aligned}
$$

where $K$ matrix, $K=N_{\alpha}^{T}\left[\int_{0}^{L}\left(B^{T} S B\right) d z^{\prime}\right] N_{\alpha}$, is the element stiffness matrix.

The method to compute the element mass matrix is similar to the definition of the stiffness matrix. The element mass matrix is obtained from the kinetic energy as follows 


$$
T=\frac{1}{2} \int_{V} \rho \dot{r}^{T} \dot{r} d V
$$

where $\rho, \dot{r}$, and $V$ are the mass density, velocity of the material point inside the beam element, and volume of body, respectively. The velocity of the material point inside the beam element at the sectional coordinate $r^{\prime}=\left\{x^{\prime}, \quad y^{\prime}, \quad 0\right\}^{T}$ can be expressed as follows

$$
\dot{r}=\dot{u}+\dot{\theta} \times r^{\prime}
$$

where $u=\left\{\begin{array}{lll}u_{x^{\prime}}, & u_{y^{\prime}}, & u_{z^{\prime}}\end{array}\right\}^{T}$ and $\theta=\left\{\begin{array}{lll}\theta_{x^{\prime}}, & \theta_{y^{\prime}}, & \theta_{z^{\prime}}\end{array}\right\}^{T}$. Therefore, equation (19) can be explained as follows

$$
\dot{r}=\left[I \mid-\left[r^{\prime} \times I\right]\right] \dot{q}
$$

where $[(\cdot) \times I]$ means the skew symmetric matrix associated with the vector $(\cdot)$.

By applying the same shape function as the stiffness matrix, equation (20) can be illustrated as follows

$$
\dot{r}=\left[I \mid-\left[r^{\prime} \times I\right]\right] N\left(z^{\prime}\right) \dot{\alpha}
$$

By substituting equation (21) into equation (18) the kinetic energy of the beam can be extended as follows

$$
\begin{aligned}
& T=\int_{0}^{L}\left(\int_{A}\left(\frac{1}{2} \rho \dot{r}^{T} \dot{r}\right) d A\right) d z^{\prime} \\
& =\frac{1}{2} \dot{\alpha}^{T} \int_{0}^{L}\left(N ( z ^ { \prime } ) ^ { T } \left(\int _ { A } \rho [ \begin{array} { c } 
{ I } \\
{ - [ r ^ { \prime } \times I ] ^ { T } }
\end{array} ] \left[\begin{array}{ll}
I & \left.\left.\left.-\left[r^{\prime} \times I\right]\right] d A\right) N\left(z^{\prime}\right)\right) d z^{\prime} \dot{\alpha}
\end{array}\right.\right.\right. \\
& =\frac{1}{2} \dot{\alpha}^{T} \int_{0}^{L}\left(N\left(z^{\prime}\right)^{T} E N\left(z^{\prime}\right)\right) d z^{\prime} \dot{\alpha}
\end{aligned}
$$

where $A$ is the cross-sectional area and $E$ matrix, $E=\int_{A} \rho\left[\begin{array}{c}I \\ -\left[r^{\prime} \times I\right]^{T}\end{array}\right]\left[I \mid-\left[r^{\prime} \times I\right]\right] d A$, is the cross-sectional mass matrix.

From the equation (16) $\dot{\alpha}$ can be obtained by differentiating $\alpha$ with respect to time as follows

$$
\dot{\alpha}=N_{\alpha} \dot{d}
$$

Inserting equation (23) into equation (22) the kinetic energy in terms of nodal degrees of 
freedom for the velocity can be obtained as follows

$$
\begin{aligned}
T & =\frac{1}{2} \dot{d}^{T} N_{\alpha}{ }^{T}\left[\int_{0}^{L}\left(N\left(z^{\prime}\right)^{T} E N\left(z^{\prime}\right)\right) d z^{\prime}\right] N_{\alpha} \dot{d} \\
& =\frac{1}{2} \dot{d}^{T} M \dot{d}
\end{aligned}
$$

where $M$ matrix, $M=N_{\alpha}^{T}\left[\int_{0}^{L}\left(N\left(z^{\prime}\right)^{T} E N\left(z^{\prime}\right)\right) d z^{\prime}\right] N_{\alpha}$, is the element mass matrix.

\subsection{Multibody formulation}

The HAWC2 is a multibody based nonlinear aeroelastic in-house code. ${ }^{40,41}$ The formulation used is the one called Floating Frame of Reference. ${ }^{42}$ In this formulation the kinematics of the flexible body is described in a coordinate system which is translated and rotated relative to an inertial system. Figure 2 shows a sketch of the flexible body coordinates.

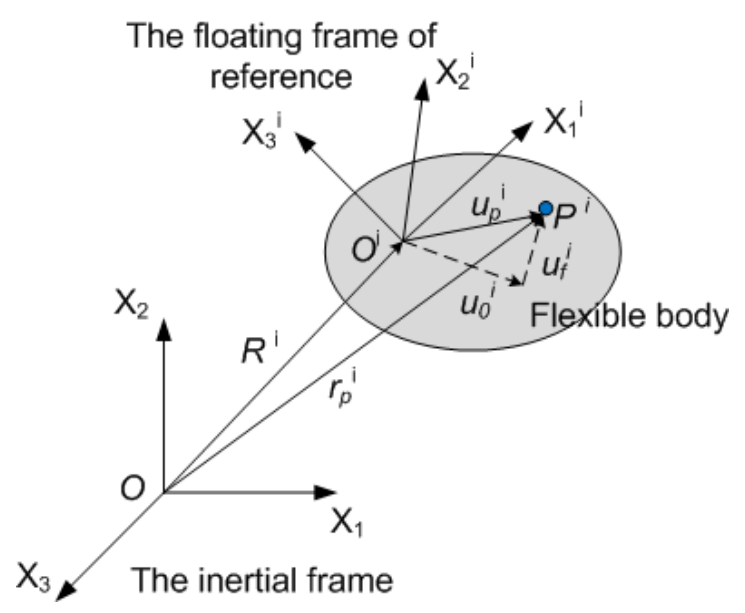

Figure 2. A sketch of a flexible body coordinate system in HAWC2

The position of a point in the flexible body $\left(O^{i}\right)$ is explained as follows

$$
r_{p}^{i}=R^{i}+A^{i} \bar{u}_{p}^{i}
$$

where the superscript $i$ represents $i$ th flexible body, $R^{i}$ is the vector from the origin of the inertial frame to the origin of the floating frame, $A^{i}$ is the rotation transformation matrix which transforms a vector from the floating frame to the inertial frame, and $\bar{u}_{p}^{i}$ is the position of the point in the floating frame coordinates. In general, the overbar of a vector in this paper represents that the coordinates refer to the floating frame of reference. The vector $\bar{u}_{p}^{i}$ is the sum of the location of the material point, $P^{i}$, when the flexible body is undeformed and when the flexible body is deformed, i.e.

$$
\bar{u}_{p}^{i}=\bar{u}_{0}^{i}+\bar{u}_{f}^{i}=\bar{u}_{0}^{i}+S^{i} q_{f}^{i}
$$


where $\bar{u}_{0}^{i}$ is the location of the material point of the undeformed flexible body and $\bar{u}_{f}^{i}$ is the deflection of the material point of the deformed flexible body. The deflection $\bar{u}_{f}^{i}$ is described by the shape function, $S^{i}$, and the degrees of freedom of the flexible body, $q_{f}^{i}$. The size of $S^{i}$ matrix is a 3 by considered number of degrees of freedom and the size of $q_{f}^{i}$ vector is a number of considered degrees of freedom.

The velocity of a point in the flexible body is able to be derived by differentiating equation (25) with respect to time as follows

$$
\dot{r}_{p}^{i}=\dot{R}^{i}+\dot{A}^{i} \bar{u}_{p}^{i}+A^{i} \dot{\bar{u}}_{p}^{i}=\dot{R}^{i}+\dot{A}^{i} \bar{u}_{p}^{i}+A^{i} S^{i} \dot{q}_{f}^{i}
$$

where $\dot{\bar{u}}_{0}^{i}=0$.

The central term on the right hand side of equation (27) can be rewritten in order to express all terms in the equation as velocity terms as follows

$$
\dot{A}^{i} \bar{u}_{p}^{i}=-A_{i}\left(\bar{u}_{p}^{i} \times \bar{\omega}^{i}\right)
$$

where $\bar{\omega}^{i}$ is the angular velocity vector.

By substituting equation (28) into equation (27) the velocity of a point can be illustrated in a matrix form as follows

$$
\dot{r}_{p}^{i}=\left[I\left|-A^{i}\left[\bar{u}_{p}^{i} \times I\right]\right| A^{i} S^{i}\right]\left[\begin{array}{c}
\dot{R}^{i} \\
\bar{\omega}^{i} \\
\dot{q}_{f}^{i}
\end{array}\right]=H^{i} \dot{q}^{i}
$$

where $\dot{q}^{i}$ is the total generalized velocity vector of the $i$ th body.

The acceleration of a point in the flexible body is determined by differentiating equation (29) with respect to time as follows

$$
\begin{aligned}
\ddot{r}_{p}^{i} & =\dot{H}^{i} \dot{q}^{i}+H^{i} \ddot{q}^{i} \\
& =\left[I\left|-A^{i}\left[\bar{u}_{p}^{i} \times I\right]\right| A^{i} S^{i}\right]\left[\begin{array}{c}
\ddot{R}^{i} \\
\dot{\bar{\omega}}^{i} \\
\ddot{q}_{f}^{i}
\end{array}\right]+A^{i}\left\{\bar{\omega}^{i} \times\left(\bar{\omega}^{i} \times \bar{u}_{p}^{i}\right)+2 \bar{\omega}^{i} \times \dot{\bar{u}}_{p}^{i}\right\}
\end{aligned}
$$

where $\ddot{R}^{i}$ is the absolute acceleration of the origin of the body frame, $\bar{\omega}^{i} \times\left(\bar{\omega}^{i} \times \bar{u}_{p}^{i}\right)$ is the centrifugal acceleration, $\dot{\bar{\omega}}^{i} \times \bar{u}_{p}^{i}$ is the angular acceleration, $2 \bar{\omega}^{i} \times \dot{\bar{u}}_{p}^{i}$ is the Coriolis acceleration, and $\ddot{\bar{u}}_{p}^{i}$ is the acceleration of the considered point due to the body deformation. 


\subsection{Application to the new beam element}

The beam element is described in an element coordinate system, $\left(x^{\prime}, y^{\prime}, z^{\prime}\right)$ which is fixed relative to the floating frame coordinate system. The element coordinate system is coinciding with the center line of the beam element. Therefore, the $\mathrm{z}$-axis, $z^{\prime}$, is coinciding with the center line and the $\mathrm{x}$ - and $\mathrm{y}$-axes, $x^{\prime}$ and $y^{\prime}$, are rotated so that they are orientated in the major axis directions of the beam element system.

The initial location of the beam element is described by the two vectors, $\bar{r}_{1}$ and $\bar{r}_{12}$ defined in the floating reference coordinates, where $\bar{r}_{1}$ describes the location of the node 1 (on which the origin of the element coordinate system is placed) from the origin of the floating reference coordinates, and $\bar{r}_{12}$ is the vector from node 1 to node 2 located at the $(0,0, L)$ in the element coordinate system. The transformation from the element coordinate system to the floating frame coordinate system is described by the orthonormal transformation matrix, $T_{E S}$ which is a 3 by 3 matrix. Using the description above, $\bar{u}_{0}^{i}$ is expressed as

$$
\bar{u}_{0}^{i}=\left\{x_{1}^{i}, \quad x_{2}^{i}, \quad x_{3}^{i}\right\}^{T}=\bar{r}_{1}+\bar{r}_{12} \frac{z^{\prime}}{L}+T_{E S} \hat{r}_{x y}
$$

where the vector $\hat{r}_{x y}$ is defined as

$$
\hat{r}_{x y}=\left\{x^{\prime}, \quad y^{\prime}, \quad 0\right\}^{T}
$$

The shape function matrix $S^{i}$ is defined as

$$
S^{i}=T_{E S} N_{T} N_{Z} T_{E S^{4}}^{T}
$$

where

$$
T_{E S^{4}}=\left[\begin{array}{cccc}
T_{E S} & 0 & 0 & 0 \\
0 & T_{E S} & 0 & 0 \\
0 & 0 & T_{E S} & 0 \\
0 & 0 & 0 & T_{E S}
\end{array}\right]
$$

The role of the $T_{E S^{4}}{ }^{T}$ matrix is to transform the nodal degrees of freedom from the floating frame coordinates to the element coordinate system. The $N_{Z}$ matrix, which is a 6 by 12 dimensional matrix, is a function of $z^{\prime}$ only and provides the deflections and the rotations of the center line, i.e. 


$$
\left\{\begin{array}{l}
u_{x^{\prime}} \\
u_{y^{\prime}} \\
u_{z^{\prime}} \\
\theta_{x^{\prime}} \\
\theta_{y^{\prime}} \\
\theta_{z^{\prime}}
\end{array}\right\}=\left\{\begin{array}{l}
u^{E} \\
\theta^{E}
\end{array}\right\}=N_{Z} T_{E S^{4}}{ }^{T} q_{f}^{i}
$$

where $N_{Z}$ can be explained by $N\left(z^{\prime}\right)$ and $N_{\alpha}$ from equations (4) and (16). Therefore, $6 \times 6 N_{i} \quad 6 N_{i} \times 12$

equation (35) is illustrated as follows

$$
\underset{6 \times 12}{N_{Z} T_{E S^{4}}{ }^{T} q_{f}^{i}=\underset{6 \times 6 N_{i}}{N} \quad \underset{6 N_{i} \times 12}{N\left(z^{\prime}\right) N_{\alpha}} T{ }^{T} q_{f}^{i}}
$$

The rotation of the cross section results in further deflection of points located away from the center line. This displacement is handled by the 3 by 6 dimensional matrix $N_{T}$ given by

$$
N_{T}=\left[\begin{array}{ccc|ccc}
1 & 0 & 0 & 0 & 0 & -y^{\prime} \\
0 & 1 & 0 & 0 & 0 & x^{\prime} \\
0 & 0 & 1 & y^{\prime} & -x^{\prime} & 0
\end{array}\right]=\left[I \mid-\left[\hat{r}_{x y} \times I\right]\right]
$$

Matrix multiplication of $N_{T}$ in front of equation (36) results in the deflection of the point $\left(x^{\prime}, y^{\prime}, z^{\prime}\right)$ in element coordinates and what is left in order to have the description of $S^{i}$ in equation (33) is to transform this vector into the floating frame coordinate system by premultiplication of $T_{E S}$.

Inertia forces can be derived from the virtual work principle as follows

$$
\delta W^{i}=\int_{V^{i}} \delta r^{i} \cdot \rho \ddot{r}^{i} d V^{i}
$$

where $\delta r^{i}$ is the virtual displacement of the material point on the surface of the element and $\ddot{r}^{i}$ is the acceleration of the material point.

From equations (25) and (28) the virtual displacement can be illustrated as follows

$$
\delta r^{i}=\delta R^{i}+\delta A^{i} \bar{u}_{p}^{i}+A^{i} S^{i} \delta q_{f}^{i}=\left[I\left|-A^{i}\left[\bar{u}_{p}^{i} \times I\right]\right| A^{i} S^{i}\right]\left[\begin{array}{c}
\delta R^{i} \\
\delta \theta^{i} \\
\delta q_{f}^{i}
\end{array}\right]=H^{i} \delta q^{i}
$$

By substituting equations (30) and (39) into equation (38), the virtual work can be illustrated as follows 


$$
\begin{array}{r}
\delta W^{i}=\left(\delta q^{i}\right)^{T} \int_{V^{i}} \rho^{i}\left[\begin{array}{c}
I \\
-\left[\bar{u}_{p}^{i} \times I\right]^{T}\left(A^{i}\right)^{T} \\
\left(S^{i}\right)^{T}\left(A^{i}\right)^{T}
\end{array}\right]\left\{\left[I\left|-A^{i}\left[\bar{u}_{p}^{i} \times I\right]\right| A^{i} S^{i}\right]\left[\begin{array}{c}
\ddot{R}^{i} \\
\dot{\bar{\omega}}^{i} \\
\ddot{q}_{f}^{i}
\end{array}\right]\right. \\
\left.+A^{i}\left(\bar{\omega}^{i} \times\left(\bar{\omega}^{i} \times \bar{u}_{p}^{i}\right)+2 \bar{\omega}^{i} \times \dot{\bar{u}}_{p}^{i}\right)\right\} d V^{i} \\
=\left(\delta q^{i}\right)^{T}\left(M^{i}\left[\begin{array}{c}
\ddot{R}^{i} \\
\dot{\bar{\omega}}^{i} \\
\ddot{q}_{f}^{i}
\end{array}\right]+Q^{i}\right)
\end{array}
$$

where $M^{i}$ is the mass matrix of $i$ th body and $Q^{i}$ is the force vector on $i$ th body related with centrifugal and Coriolis forces. They can be explained as follows

$$
\begin{gathered}
M^{i}=\int_{V^{i}} \rho^{i}\left[\begin{array}{ccc}
I & -A^{i}\left[\bar{u}_{p}^{i} \times I\right] & A^{i} S^{i} \\
\cdots & {\left[\bar{u}_{p}^{i} \times I\right]^{T}\left[\bar{u}_{p}^{i} \times I\right]} & -\left[\bar{u}_{p}^{i} \times I\right]^{T} S^{i} \\
\operatorname{sym} . & \left(S^{i}\right)^{T} S^{i}
\end{array}\right] d V^{i} \\
Q^{i}=\int_{V^{i}} \rho^{i}\left[\begin{array}{c}
A^{i}\left(\bar{\omega}^{i} \times\left(\bar{\omega}^{i} \times \bar{u}_{p}^{i}\right)+2 \bar{\omega}^{i} \times \dot{\bar{u}}_{p}^{i}\right) \\
{\left[\bar{u}_{p}^{i} \times I\right]\left(\bar{\omega}^{i} \times\left(\bar{\omega}^{i} \times \bar{u}_{p}^{i}\right)+2 \bar{\omega}^{i} \times \dot{\bar{u}}_{p}^{i}\right)} \\
\left(S^{i}\right)^{T}\left(\bar{\omega}^{i} \times\left(\bar{\omega}^{i} \times \bar{u}_{p}^{i}\right)+2 \bar{\omega}^{i} \times \dot{\bar{u}}_{p}^{i}\right)
\end{array}\right] d V^{i}
\end{gathered}
$$

\section{NUMERICAL RESULTS}

After implementing the new beam element into HAWC2 three different cases are investigated in order to validate the new beam model with a single body and a multibody configuration. The first case is used for validating the developed beam element with an anisotropic single body example. The second example case is used for validating the multibody formulation used in HAWC2. As the last case a whole turbine configuration including anisotropic blades on the rotor is considered for validating the beam element in the multibody formulation. Figure 3(a) and (b) show the sketches of the considered first and second case. The last considered case is the NREL $5 \mathrm{MW}$ reference wind turbine ${ }^{45}$. Tables 1 and 2 show the detailed structural properties and crosssectional stiffness matrix for the first and the second example. More detailed information is addressed in Hodges et l. $^{46}$ and Simo et al. ${ }^{47}$. 

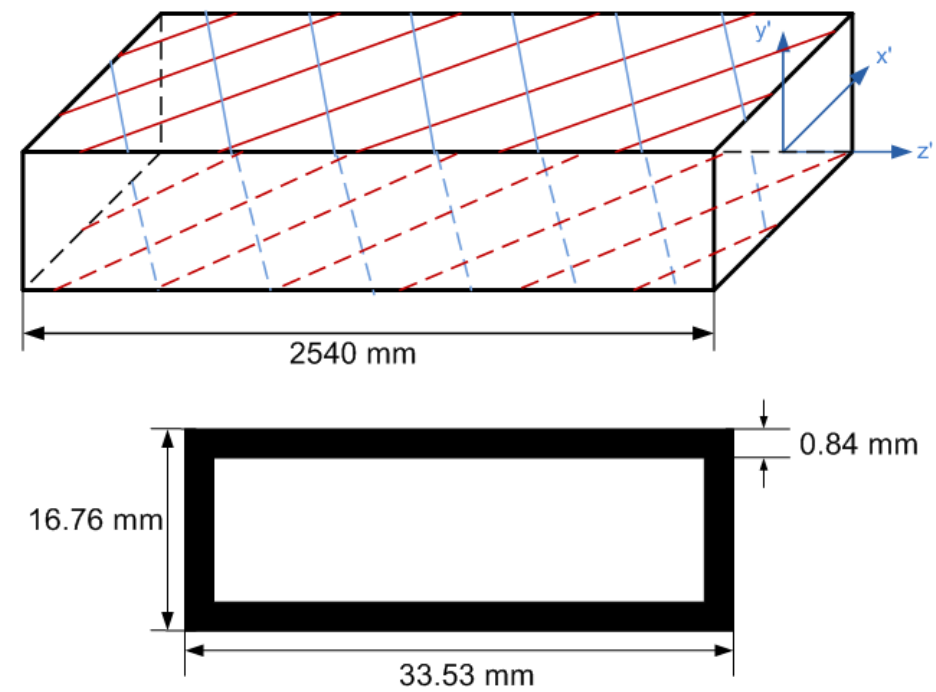

(a) Case 1: an anisotropic rectangular box beam, $\left[20^{\circ} /-70^{\circ} / 20^{\circ} /-70^{\circ} /-70^{\circ} / 20^{\circ}\right]_{\mathrm{T}}$ layups with T300/5208 Graphite/Epoxy ${ }^{46}$

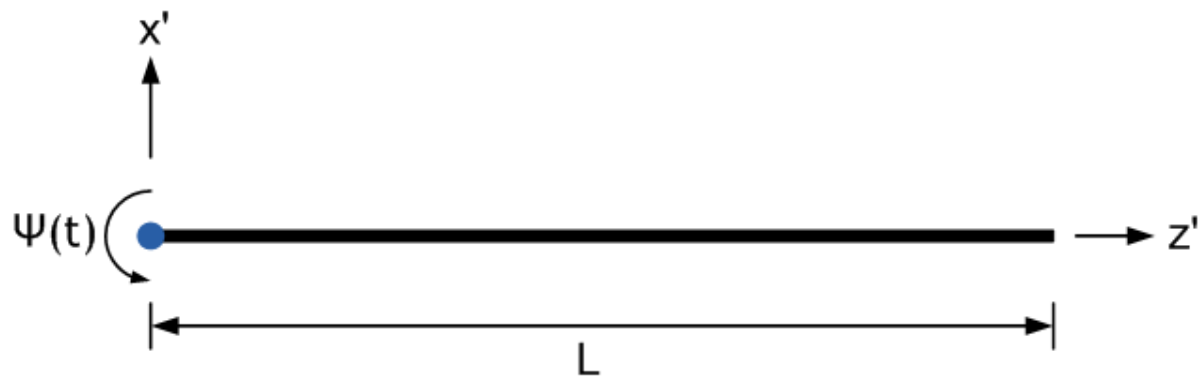

(b) Case 2: a spin-up maneuver problem by prescribing the angle ${ }^{47}$

Figure 3. A sketch of considered examples

\subsection{Validation of the new beam finite element with an anisotropic single body}

Case 1 is used for validating the beam element with an anisotropic single body configuration. The case produces structural couplings due to asymmetric composite layups such as edgewise deflection-flapwise bending $\left(\mathrm{S}_{14}\right)$, flapwise deflection-edgewise bending $\left(\mathrm{S}_{25}\right)$, axial deflectiontorsion $\left(\mathrm{S}_{36}\right)$. Natural frequencies computed from HAWC2 are compared to the other existing results obtained from Hodges et $\mathrm{al}^{46}$ and the results determined by a commercial software, MSC/Nastran. In order to compute the natural frequencies by MSC/Nastran, a 4-node shell element located in the mid-thickness of the material is considered. The structure is meshed with 38 elements circumferentially and 1015 longitudinally. Table 3 shows the natural frequencies comparison. The HAWC2 result shows good agreement.

The mentioned coupling effects on the structure can be captured through the mode shape analysis. Figure 4 shows the first 6 mode shapes obtained from HAWC2. In this figure it is exhibited by all modes that the flap related mode is coupled with the edge related mode and vice versa. First two modes produce small coupling effects and therefore it is not easy to see the 
coupled behaviors. However, at the higher modes it is very obvious that the flap and edge related mode is coupled with the edge and flap related mode, respectively.
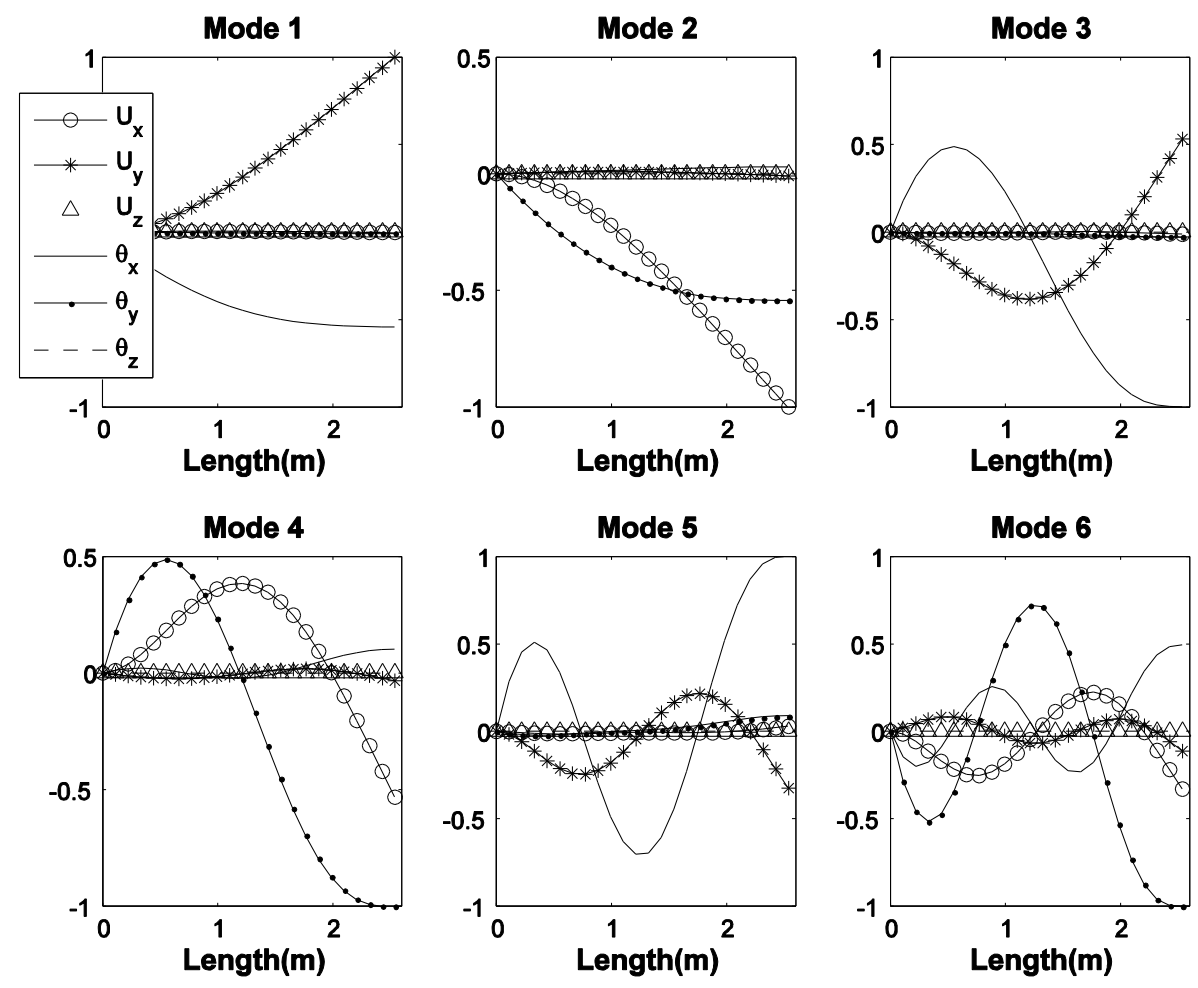

Figure 4. 6 mode shapes of Case 1 with anisotropic properties

From the above natural frequencies and mode shapes results it may be concluded that the beam model can capture the physical behaviors of a structurally coupled single body very well. More validations with an anisotropic single body concept were performed by the authors. ${ }^{48}$

\subsection{Validation of a nonlinear multibody formulation}

Case 2 is used for validating a nonlinear multibody formulation. This example is known as the Spin-up Maneuver subjected to the angle, $\psi(t)$, described in equation (43). The angle is applied at the root of the beam shown in Figure 3(b). The angle is scheduled with respect to time as follows

$$
\begin{aligned}
& \psi(t)=\frac{2}{5}\left[\frac{t^{2}}{2}+\left(\frac{15}{2 \pi}\right)^{2}\left(\cos \frac{2 \pi t}{15}-1\right)\right] \mathrm{rad}, \quad 0 \leq t \leq 15 \mathrm{sec} \\
& \psi(t)=(6 t-45) \mathrm{rad}, \quad t>15 \mathrm{sec}
\end{aligned}
$$

where this type of motion was suggested by Kane et al. ${ }^{49}$.

Tip displacements on $x^{\prime}$ and $z^{\prime}$ direction are compared between HAWC2 and the existing results obtained by Simo et al. ${ }^{47}$. Figure 5(a) and (b) show the tip displacements in $x^{\prime}$ and $z^{\prime}$ 
direction, respectively. They are matched very well. The centrifugal stiffening effect is captured as well. From the obtained results it can be addressed that the developed multibody formulation performs very well.

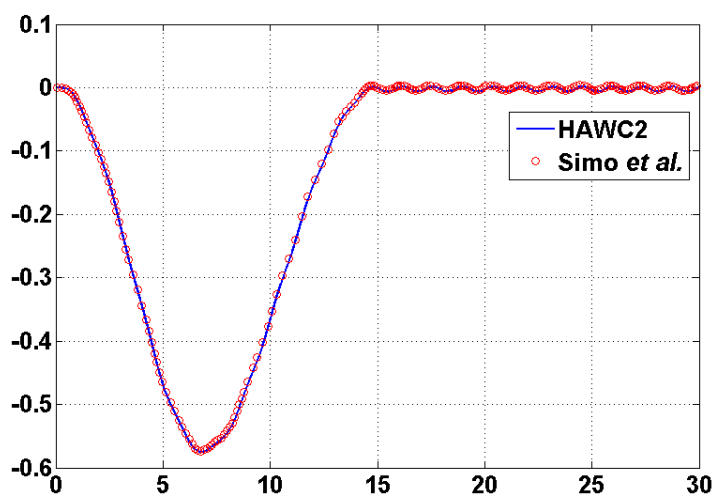

(a) Tip displacement in $x^{\prime}$ direction

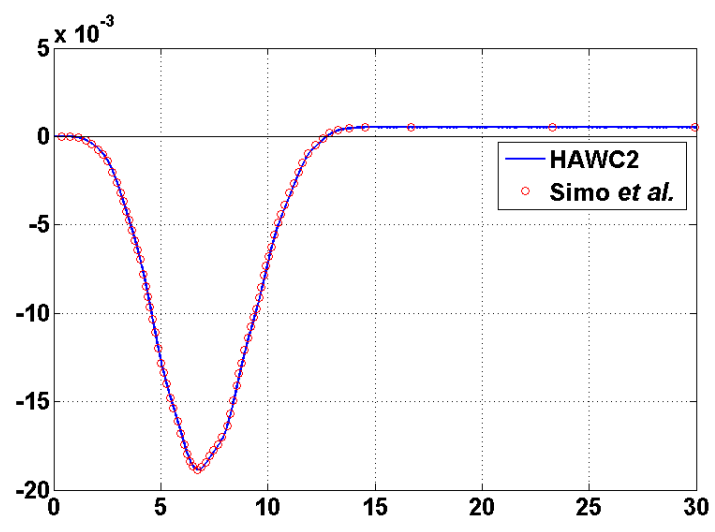

(b) Tip displacement in $z^{\prime}$ direction Figure 5. Tip displacement comparisons between HAWC2 and Simo et al. ${ }^{47}$

\subsection{Validation of a whole turbine configuration}

As the final example a whole wind turbine, $5 \mathrm{MW}$ reference wind turbine ${ }^{45}$, is considered to validate the new beam element in a multibody system. The natural frequencies of the whole turbine and the blades are compared between the standard version (i.e. before implementing the new beam element) and the new version (i.e. after implementing the new beam element). Table 4 shows the comparisons.

Natural frequencies for both the whole turbine and the blades are very similar. Thus, it may also be concluded that the developed beam element is successfully developed and implemented into HAWC2.

As a final step a parametric study is accompanied with the new version of HAWC2 to investigate an anisotropic structural effect in terms of a whole turbine response.

\subsection{A simple parametric study for a blade bend-twist coupling effect}

According to the literature ${ }^{35-39}$ the bend-twist coupled composite blade yields the benefit to reduce the blade flapwise fatigue loads. In this section, a simple parametric study is investigated with the developed structural model in order to explore whether or not the developed model is able to capture a given anisotropic effect such as a bend-twist coupling in a multibody configuration. The 5MW turbine with blades having a bend-twist coupling is used. In this study, it is not a scope to design a blade with a detailed composite layup which results in a desired bend-twist coupling. Instead, the considered bend-twist coupling is assigned based on equation (44) obtained from Lobitz et al. ${ }^{39}$ and it is assumed that such a blade can be produced. 


$$
S=\left[\begin{array}{cccccc}
k_{x} G A & 0 & 0 & 0 & 0 & 0 \\
0 & k_{y} G A & 0 & 0 & 0 & 0 \\
0 & 0 & E A & 0 & 0 & 0 \\
0 & 0 & 0 & E I_{x} & 0 & S_{B T} \\
0 & 0 & 0 & 0 & E I_{y} & 0 \\
0 & 0 & 0 & S_{B T} & 0 & G J
\end{array}\right]
$$

where $S_{B T}$ is the coupling term represented as

$$
S_{B T}=\alpha \sqrt{E I_{x} \times G J}, \quad-1<\alpha<1
$$

The amount of coupling is assigned by $\alpha$. When $\alpha$ has a negative value flapwise bending toward tower results in blade twist toward feather. It is the opposite when $\alpha$ has a positive value. In this study two fabricated coupling cases are considered which are $\alpha=-0.05$ and $\alpha=-0.17$. Both cases are producing the bend-twist coupling for which $1 m$ flapwise bending tip deflection resulting in approximately $0.3 \mathrm{deg}$ and $1 \mathrm{deg}$ twist at the blade tip, respectively. From the experiments done at DTU on the $8 \mathrm{~m}$ section from a $23 \mathrm{~m}$ Vestas blade modified with additional UD layers ${ }^{32,34}$ the bend-twist coupling was measured. The inner part was fixed with two clamps and the outer part was loaded at a movable clamp. It was found that in pure flapwise bending a flapwise deflection of $120 \mathrm{~mm}$ at the outer measuring section resulted in a twisting angle of $0.5 \mathrm{deg}$, which corresponds to $4.5 \mathrm{deg}$ for $1 \mathrm{~m}$ tip deflection. So the bend-twist couplings used here can easily be obtained in reality. The amount of couplings can be calculated by either an Eigen vector analysis or a static analysis. In this paper a static analysis is used. A static load at the blade tip, which can produce approximately $1 \mathrm{~m}$ blade flapwise tip deflection for both cases, is applied. Figure 6(a) and (b) show results from static analyses obtained by a cantilevered blade.

A single wind speed, $7 \mathrm{~m} / \mathrm{s}$, is considered with $22 \%$ turbulence intensity. All results obtained are compared with a case with no couplings referred to as the baseline. Figure 7 shows the comparisons of the blade root flapwise, edgewise, and torsional equivalent fatigue loads and blade tip deflection. The negative sign means that the obtained values are lower than for the baseline. The S-N slope, $m=12$, for a composite material is selected for the equivalent fatigue load analysis. Rainflow counting methodology ${ }^{50}$ is adapted for fatigue analysis. The blade root flapwise, edgewise, and torsional equivalent fatigue load are decreased up to approximately $2 \%$, $0.5 \%$, and $10 \%$, respectively when $\alpha=-0.05$. When $\alpha=-0.17,20 \%, 0.8 \%$ and $21 \%$ of the flapwise, edgewise, and torsional equivalent fatigue loads are reduced. The blade tip clearances are also improved for both cases, approximately $8 \%$ and $21 \%$, respectively.

One of the main reasons to obtain the above results is that aerodynamic loads on the blades are reduced due to reduced angle of attack resulting from torsion toward feather. Figure 8 shows the comparison of the mean value of angle of attack. The angles of attack for both cases are reduced, approximately $11 \%$ and $33 \%$. The more coupling provides the more angle of attack changes resulting to decreasing the loads and the flapwise deflection. However, this phenomenon is able to decrease the mechanical power (i.e. the power transmitted through a mechanical system). But it is out of scope with the present study to investigate more detailed advantages and disadvantages of the bend-twist coupling. From the study it is very clearly seen that the current structural model is able to capture the anisotropic effects. 

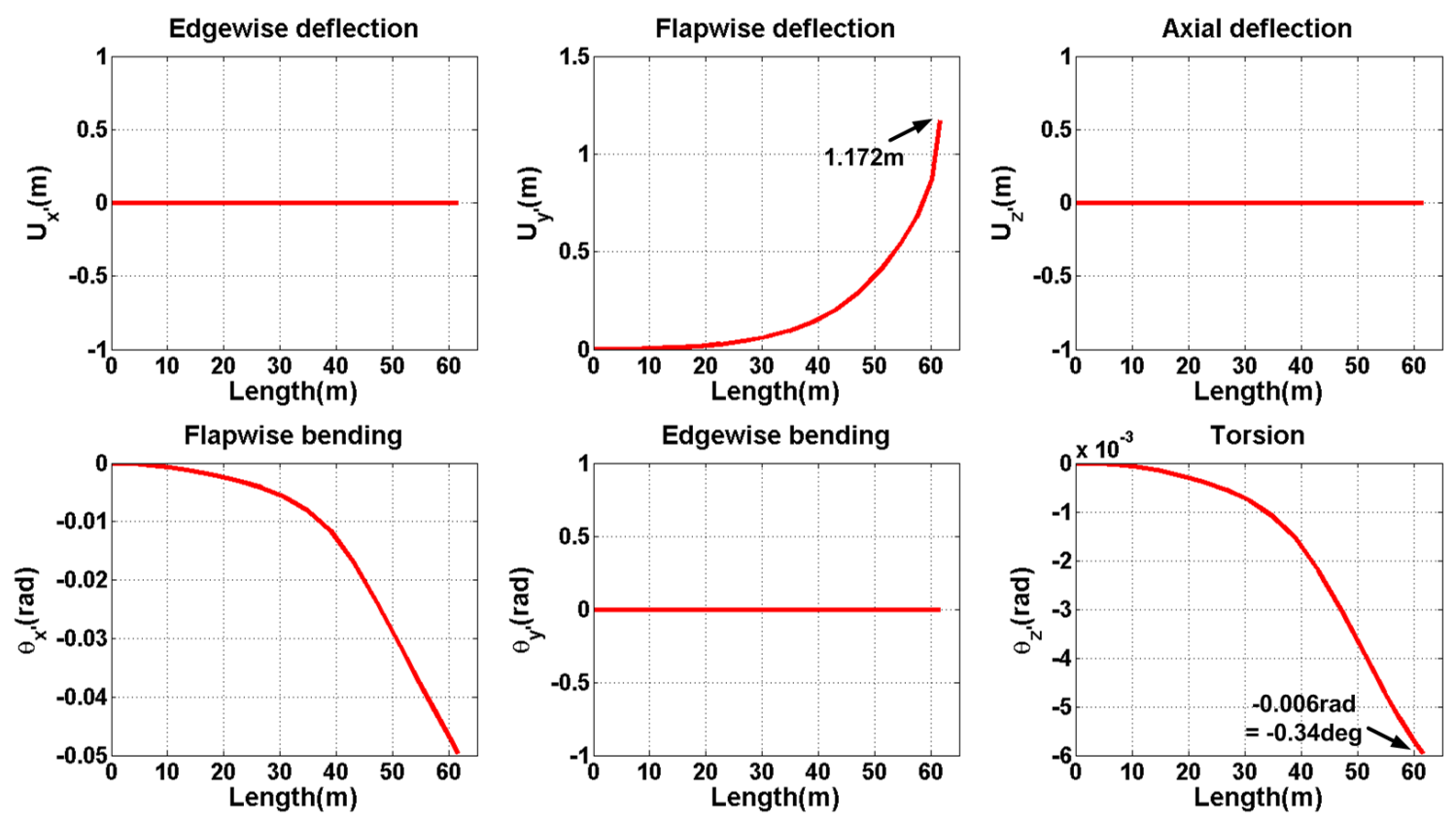

(a) Example 1: $\alpha=-0.05$
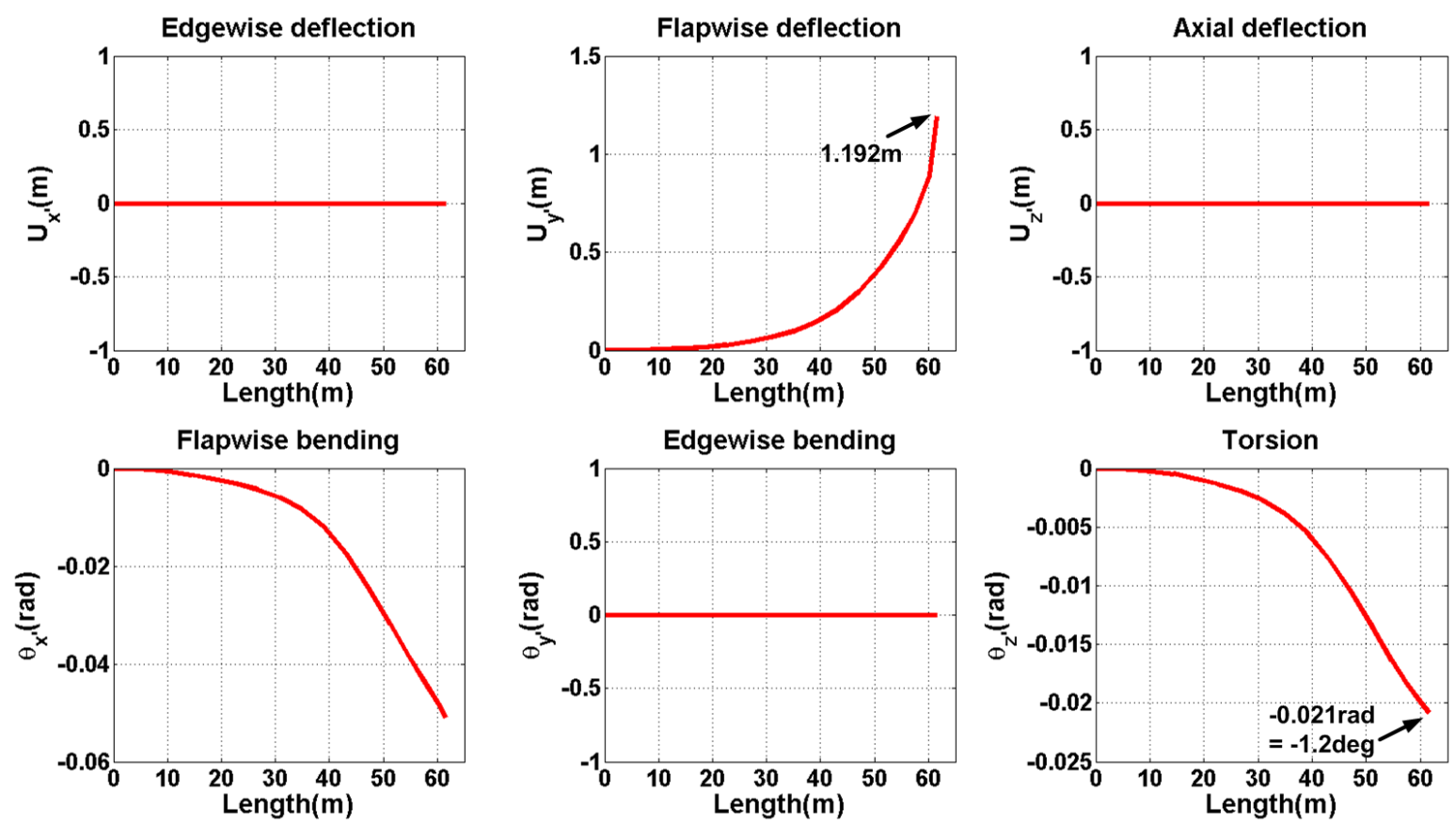

(b) Example 2: $\alpha=-0.17$

Figure 6. The static deflections and rotations of the coupled beam 


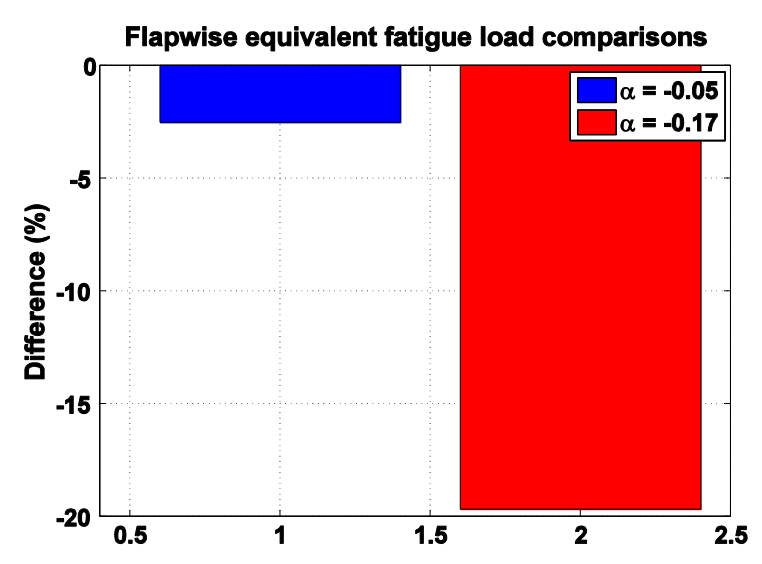

(a) Flapwise equivalent fatigue load

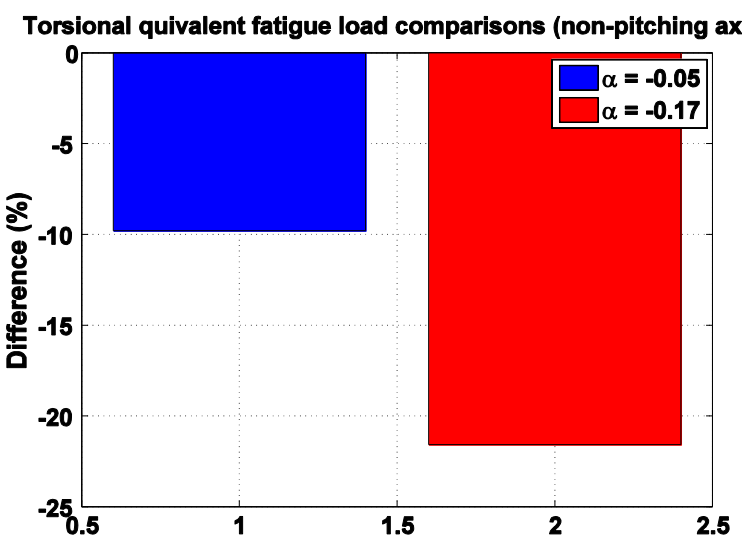

(c) Torsional equivalent fatigue load

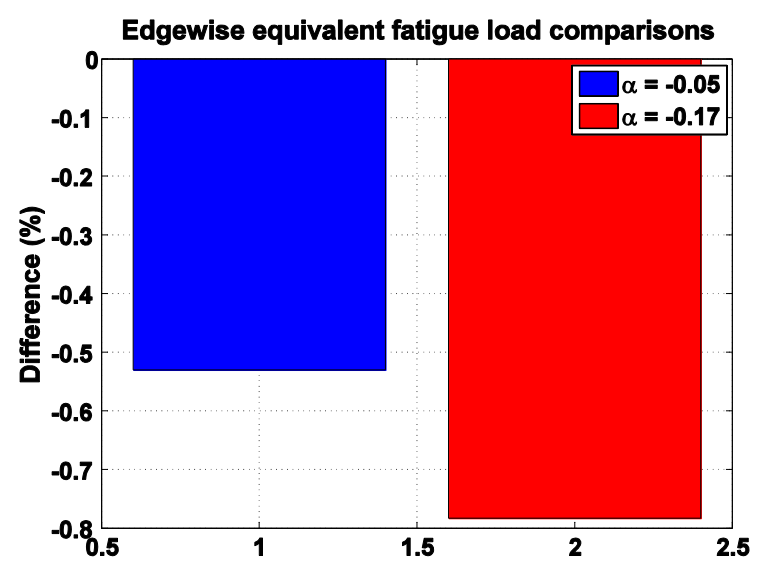

(b) Edgewise equivalent fatigue load Maximum tip deflection comparisons

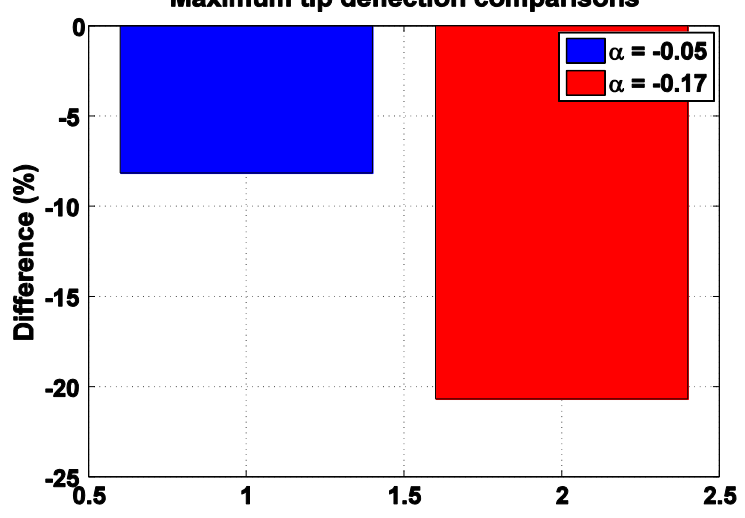

(d) Maximum blade tip deflection

Figure 7: Equivalent fatigue loads and maximum tip deflection comparisons

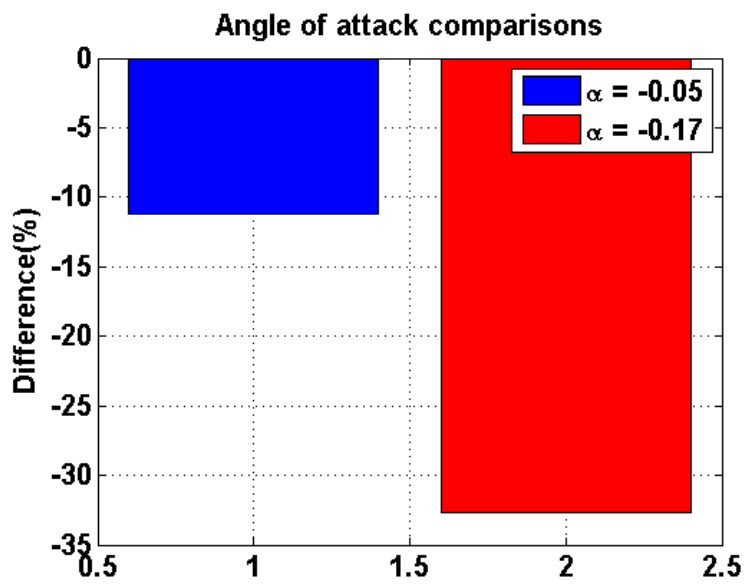

Figure 8. Angle of attack comparisons 


\section{CONCLUSIONS}

In this paper a new beam element, which is able to take the behavior of anisotropic materials into account, is developed and implemented into the multibody system of HAWC2. Validations for a single body and a multibody configuration are performed with an anisotropic beam model, a spin-up maneuver problem and the NREL 5MW reference wind turbine. Eigenvalue analyses are performed. A static analysis is also performed with the purpose of investigating a structural coupling effect on the $5 \mathrm{MW}$ reference wind turbine. A parametric study is performed to examine if the developed structural model in a multibody system is able to capture the given anisotropic structural coupling effects. Obtained results can be summarized as follows

- Case 1: Natural frequencies are compared between HAWC2 computations and computations from other methods. The obtained results from HAWC2 are very similar to those obtained from the other methods. Mode shapes are also investigated. From the obtained results it is seen that the developed beam element is able to capture the given couplings well.

- Case 2: A spin-up maneuver problem by prescribed angle is examined in order to validate the developed nonlinear multibody formulation used in HAWC2. The tip displacements are compared between HAWC2 and the other published results. They match very well. From this comparison it can be concluded that the developed nonlinear multibody formulation performs very well.

- Case 3: The whole 5MW reference wind turbine is considered to investigate the newly developed beam element in a multibody system. The obtained natural frequencies between the standard version (i.e. before implementing the new beam element) and the new version (i.e. after implementing the new beam element) are very similar so it may be concluded that the implementation of the new element is successful.

- Parametric study: a simple parametric study is performed with the new version of HAWC2 to investigate a structural coupling effect in terms of blade responses. Two fictitious bendtwist coupling cases are fabricated such that $1 \mathrm{~m}$ flapwise tip deflection resulting in $0.3 \mathrm{deg}$ and 1 deg torsion at the blade tip, respectively. The angle of attack is in both cases reduced due to the torsion toward feather coupling effect. Therefore, both coupling cases are able to reduce the loads. From this parametric study it is seen that structural coupling effects are able to be examined by the developed beam element in the HAWC2 multibody system.

Next step in the ongoing research activities is to study the whole wind turbine system response, considering realistic composite tailoring effects such as bend-twist or bend-bend couplings produced by layup changes. This will bring more clear answers concerning the potential improvement of the turbine performance by smart design of the blades using structural couplings resulting from the anisotropic materials.

\section{ACKNOWLEDGEMENTS}

The work is supported by the Danish Energy Authority through the 2007 Energy Research Programme (EFP 2007). The supported EFP-project is titled "Anisotropic beam model for analysis and design of passive controlled wind turbine blades" and has journal no. 33033-0075. 
The part of this work is also funded by the EUDP-2009 project Aeroelastic optimization of MW turbines (ENS 64009-0002). The supports are gratefully acknowledged and highly appreciated.

\section{REFERENCES}

1. Hodges DH. Review of Composite Rotor Blade Modeling. AIAA Journal, Vol. 20, No. 3, 1990, pp. 561-565.

2. Kunz DL. Survey and Comparison of Engineering Beam Theories for Helicopter Rotor Blades. Journal of Aircraft, Vol. 31, No. 3, May-June 1994, pp. 473-479.

3. Friedmann PP, Tong P. Dynamic Nonlinear Elastic Stability of Helicopter Rotor Blades in Hover. NASA CR-114,485, May 1972.

4. Hodges DH, Ormiston RA. Nonlinear Equations for Bending of Rotating Beams with Application to Linear Flap-Lag Stability of Hingeless Rotors. NASA TM X-2770, May 1973.

5. Hodges DH, Dowell EH. Nonlinear Equations of Motion for the Elastic Bending and Torsion of Twisted Nonuniform Rotor Blades. NASA TN D-7818, December 1974.

6. Kaza KRV, Kvaternik RG. Nonlinear Aeroelastic Equations for Combined Flapwise Bending, Chordwise Bending, Torsion, and Extension of Twisted Nonuniform Rotor Blades in Forward Flight. NASA TM 74059, August 1977.

7. Hodges DH. Nonlinear Equations of Motion for Cantilever Rotor Blades in Hover with Pitch Link Flexibility, Twist, Precone, Droop, Sweep, Torque Offset, and Blade Root Offset. NASA TM X-73,112, May 1976.

8. Sivaneri NT, Chopra I. Dynamic Stability of a Rotor Blade Using Finite Element Analysis. AIAA Journal, Vol. 20, No. 5, 1982.

9. Kvaternik RG, Kaza KRV. Nonlinear Curvature Expressions for Combined Flapwise Bending, Chordwise Bending, Torsion, and Extension of Twisted Rotor Blades. NASA TM X-73,997, 1976.

10. Hodges DH. Nonlinear Equations for Dynamics of Pretwisted Beams Undergoing Small Strains and Large Rotations. NASA TP 2470, May 1985.

11. Simo JC. A Finite Strain Beam Formulation. The Three Dimensional Dynamic Problem. Part I. Computer methods in Applied Mechanics and Engineering, Vol. 49, 1985, pp. 5570.

12. Simo JC, Vu-Quoc L. On the Dynamics in Space of Rods Undergoing Large Motion-A Geometrically Exact Approach. Computer methods in Applied Mechanics and Engineering, Vol. 66, 1988, pp. 125-161.

13. Hodges DH. A Mixed Variational Formulation Based on Exact Intrinsic Equations for Dynamics of Moving Beams. International Journal of Solids and Structures, Vol. 26, No. 11, 1990, pp. 1253-1273.

14. Bauchau OA. A Beam Theory for Anisotropic Materials. Journal of Applied Mechanics, Vol. 52, June 1985, pp. 416-422.

15. Bauchau OA, Hong CH. Large Displacement Analysis of Naturally Curved and Twisted Composite Beams. AIAA Journal, Vol. 25, No. 11, 1987, pp. 1469-1475.

16. Bauchau OA, Hong CH. Nonlinear Composite Beam Theory. Journal of Applied Mechanics, Vol. 55, March 1988, pp. 156-163. 
17. Kosmatka JB. Structural Dynamic Modeling of Advanced Composite Propellers by the Finite Element Method. Ph.D. Dissertation, University of California, Los Angeles, CA, 1986.

18. Kosmatka JB. A Refined Theory for Advanced Composite Rotor Blade Analysis. Proceedings of the AHS National Specialists' Meeting on Advnaced Rotorcraft Structures, Williamburg, VA, 1988.

19. Giavotto V, Borri M, Mantegazza P, Ghiringhelli G, Carmaschi V, Maffioli GC, Mussi F. Anisotropic Beam Theory and Applications. Computers and Structures, Vol. 16, 1983, pp. 403-413.

20. Borri M, Ghiringhelli G, Merlini T. Linear Analysis of Naturally Curved and Twisted Anisotropic Beam. Proceedings of the International Specialists Meeting on Rotorcraft Basic Research, Atlanta, GA, 1991.

21. Hodges DH, Atilgan AR, Cesnik CES, Fulton MV. On a Simplified Strain Energy Function for Geometrically Nonlinear Behaviour of Anisotropic Beams. Composites Engineering, Vol. 2, No. 5-7, 1992, pp. 513-526.

22. Atilgan AR, Hodges DH. A Geometrically Nonlinear Analysis for Nonhomogeneous Anisotropic Beams. Proceedings of the AIAA/ASME/ASCE/AHS/ASC 30th Structures, Structural Dynamics, and Materials Conference, Washington, DC, 1989, pp. 895-908.

23. Cesnik CES, Hodges DH. VABS: A New Concept for Composite Rotor Blade Crosssectional Modeling. Journal of the American Helicopter Society, Vol. 42, No. 1, January 1997, pp. 27-38.

24. Popescu B, Hodges DH. On Asymptotically Correct Timoshenko-like Anisotropic Beam Theory. International Journal of Soilds and Structures, Vol. 37, No. 3, 1999, pp. 535-558.

25. Yu W, Hodges DH, Volovoi VV, Cesnik CES. On Timoshenko-Like Modeling of Initially Curved and Twisted Composite Beams. International Journal of Soilds and Structures, Vol. 39, No. 19, 2002, pp. 5101-5121.

26. Yu W, Volovoi VV, Hodges DH, Hong X. Validation of the Variational Asymptotic Beam Sectional Analysis. AIAA Journal, Vol. 40, No. 10, 2002, pp. 2105-2112.

27. Hodges DH. Nonlinear Composite Beam Theory. American Institute of Astronautics and Aeronautics: Virginia, 2006; 59-142.

28. Berdichevsky VL. Variational-Asymptotic Method of Constructing a Theory of Shells. PMM, Vol. 43, No. 4, 1979, pp. 664-687.

29. Kooijman HJT. Bending-torsion coupling of a wind turbine rotor blades. ECN-I-96-060, Netherlands Energy Research Foundation, Petten, December 1996.

30. Middleton V, Fitches P, Jeronimidis G, Feuchtwang J. Passive blade pitching for overspeed control of an HAWT. Proceedings of the 20th British Wind Energy Association Conference, Cardiff, September 1998.

31. Infield DG, Feuchtwang JB, Fitches P. Development and testing of a novel self-twisting wind turbine rotor. Proceedings of the 1999 European Wind Energy Conference, Nice, March 1999.

32. Berring P, Branner K, Berggreen C, Knudsen HW. Torsional performance of wind turbine blades - Part 1: Experimental investigation. International conference on composite materials (ICCM-16), Kyoto, Japan 2007.

33. Branner K, Berring P, Berggreen C, Knudsen HW. Torsional Performance of wind Turbine Blades - Part II: Numerical Validation. International conference on composite materials (ICCM-16), Kyoto, Japan 2007. 
34. Luczak M, Manzato S, Peeters B, Branner K, Berring P, Kahsin M. Dynamic Investigation of Twist-bend Coupling in a Wind Turbine Blade. Journal of Theoretical and Applied Mechanics 2011; 49(3): 765-789.

35. Lobitz DW, Veers PS, Migliore PG. Enhanced performance of HAWTs using adaptive blades. Proceedings of the 1996 ASME Wind Energy Symposium, Houston, TX, JanuaryFebruary 1996.

36. Lobitz DW, Laino DJ. Load Mitigation with Twist-Coupled HAWT Blades. Proceedings of 1999 ASME Wind Energy Symposium, Reno, NV, January 1999.

37. Lobitz DW, Veers PS, Laino DJ. Performance of twist-coupled blades on variable speed rotors. Proceedings of the 2000 ASME Wind Energy Symposium, Reno, NV, January 2000: 404-412.

38. Lobitz DW, Veers PS. Load Mitigation with Bending/Twist-coupled Bladeson Rotors Using Modern Control Strategies. Wind Energy 2003; 6: 105-117.

39. Lobitz DW, Veers PS. Aeroelastic Behavior of Twist-Coupled HAWT Blades. Proceedings of 1998 ASME Wind Energy Symposium, Reno, NV, January 1998.

40. Larsen TJ, Hansen AM. How 2 HAWC2, the user's manual. Risø-R-1597(EN), 2007.

41. Petersen JT. Kinematically Nonlinear Finite Element Model of a Horizontal Axis Wind Turbine- Part 1: Mathematical Model and Results. Ph.D. Thesis. Technical University of Denmark, 1990.

42. Shabana AA. Dynamics of Multibody System. Cambridge University Press; New York, 2005; chapter 5.

43. Larsen TJ, Hansen AM, Buhl T. Aeroelastic effects of large blade deflections for wind turbines. Proceedings of The Science of Making Torque from Wind, Delft University of Technology, Delft, Netherlands, 2004, pp. 238-246.

44. Blasques JP, Stolpe M Multi-material topology optimization of laminated composite beam cross sections. Composite Structures, Vol. 94, No. 11, November 2012, pp. 3278-3289.

45. Jonkman J, Butterfield S, Musial W, Scott G. Definition of a 5-MW Reference Wind Turbine for Offshore System Development. Technical Report NREL/TP-500-38060, February 2009.

46. Hodges DH, Atilgan AR, Fulton MV, Rehfield LW. Free-Vibration Analysis of Composite Beams. Journal of the American Helicopter Society 1991; 36(3): 36-47.

47. Simo JC, Vu-Quoc L. On the Dynamics of Flexible Beams Under Large Overall MotionThe Plane Case: Part II. Journal of Applied Mechanics 1986; 53(12): 855-863.

48. Kim T, Branner K, Hansen AM. Parametric Study of Composite Wind Turbine Blades. In Proceedings of 32nd Ris $\phi$ International Symposium on Materials Science, Roskilde, Denmark, September 5-9 2011.

49. Kane TR, Ryan RR, Banerjee AK. Dynamics of a Beam Attached to a Moving Base. AAS/AIAA Astrodynamics Specialist Conference, Vail, CO, August 1985.

50. Matsuiski M, Endo T. Fatigue of metals subjected to varying stress. Japan Society of Mechanical Engineering, Fukuoka, Japan, 1968. 


\section{Tables}

Table 1. Sectional properties of Case 1

\begin{tabular}{cc}
\hline Material & T300/5208 Graphite/Epoxy \\
properties & Rectangular box beam \\
$E_{11}$ & $11.03 \mathrm{GPa}$ \\
$E_{33}$ & $146.79 \mathrm{GPa}$ \\
$G_{12}$ & $4.82 \mathrm{GPa}$ \\
$G_{13}, G_{23}$ & $6.20 \mathrm{GPa}$ \\
$v_{12}$ & 0.28 \\
$P$ & $1599 \mathrm{~kg} / \mathrm{m}^{3}$ \\
\hline \hline Sectional stiffness of Case $1\left(\mathrm{Hodges}\right.$ et al. $\left.{ }^{46}\right)$ \\
\hline$S_{11}\left(k_{x} G A\right)$ & $7.7440 \times 10^{5}(\mathrm{~N})$ \\
$S_{14}$ & $8.3266 \times 10^{3}(\mathrm{~N}-\mathrm{m})$ \\
$S_{22}\left(k_{y} G A\right)$ & $2.9557 \times 10^{5}(\mathrm{~N})$ \\
$S_{25}$ & $9.0666 \times 10^{3}\left(\mathrm{~N}-\mathrm{m}^{2}\right)$ \\
$S_{33}(E A)$ & $5.0574 \times 10^{6}(\mathrm{~N})$ \\
$S_{36}$ & $-1.7195 \times 10^{4}\left(\mathrm{~N}-\mathrm{m}^{2}\right)$ \\
$S_{44}\left(E I_{x}\right)$ & $2.4576 \times 10^{2}\left(\mathrm{~N}-\mathrm{m}^{2}\right)$ \\
$S_{55}\left(E I_{y}\right)$ & $7.4439 \times 10^{2}\left(\mathrm{~N}-\mathrm{m}^{2}\right)$ \\
$S_{66}(G J)$ & $1.5040 \times 10^{2}\left(\mathrm{~N}-\mathrm{m}^{2}\right)$ \\
\hline
\end{tabular}

Table 2. Sectional properties of Case 2

\begin{tabular}{cc}
\hline$A \rho$ & $1.2 \mathrm{~kg} / \mathrm{m}$ \\
$I \rho$ & $6.0 \times 10^{-4} \mathrm{~kg}-\mathrm{m}$ \\
$L$ & $10 \mathrm{~m}$ \\
\hline \hline \multicolumn{2}{l}{ Sectional stiffness of Case $2\left(\right.$ Simo et al $\left.^{47}\right)$} \\
\hline$S_{11}\left(k_{x} G A\right)$ & $1.0000 \times 10^{7}(\mathrm{~N})$ \\
$S_{22}\left(k_{y} G A\right)$ & $1.0000 \times 10^{7}(\mathrm{~N})$ \\
$S_{33}(E A)$ & $2.8000 \times 10^{7}(\mathrm{~N})$ \\
$S_{44}\left(E I_{x}\right)$ & $1.4000 \times 10^{4}\left(\mathrm{~N}-\mathrm{m}^{2}\right)$ \\
$S_{55}\left(E I_{y}\right)$ & $1.4000 \times 10^{4}\left(\mathrm{~N}-\mathrm{m}^{2}\right)$ \\
$S_{66}(G J)$ & $9.9821 \times 10^{3}\left(\mathrm{~N}-\mathrm{m}^{2}\right)$ \\
\hline
\end{tabular}


Table 3: Natural frequencies comparison of Case 1

\begin{tabular}{cccc}
\hline Mode & HAWC2 $[\mathrm{Hz}]$ & Case 1 & \\
\hline 1 (flap-edge) & 3.00 & 3.00 & MSC/Nastran $[\mathrm{Hz}]$ \\
2 (edge-flap) & 5.19 & 5.19 & 2.98 \\
3 (flap-edge) & 18.79 & 19.04 & 5.12 \\
4 (edge-flap) & 32.41 & 32.88 & 18.65 \\
5 (flap-edge) & 52.57 & 54.69 & 32.02 \\
6 (edge-flap) & 89.54 & & 52.17 \\
\hline
\end{tabular}

Table 4: The natural frequencies comparisons

\begin{tabular}{ccc||ccc}
\hline \multicolumn{3}{c}{$\begin{array}{c}\text { Whole turbine natural frequency }[\mathrm{Hz}] \\
\text { (structure) }\end{array}$} & \multicolumn{3}{c}{$\begin{array}{c}\text { Blade natural frequency }[\mathrm{Hz}] \\
\text { (body) }\end{array}$} \\
\hline & Standard version & New version & & \multicolumn{3}{c}{ Standard version } & New version \\
\hline 1 & $3.17017 \times 10^{-1}$ & $3.17004 \times 10^{-1}$ & 1 & $6.72048 \times 10^{-1}$ & $6.71166 \times 10^{-1}$ \\
2 & $3.19657 \times 10^{-1}$ & $3.19631 \times 10^{-1}$ & 2 & $1.07864 \times 10^{0}$ & $1.07804 \times 10^{0}$ \\
3 & $6.06803 \times 10^{-1}$ & $6.06571 \times 10^{-1}$ & 3 & $1.93946 \times 10^{0}$ & $1.93328 \times 10^{0}$ \\
4 & $6.31398 \times 10^{-1}$ & $6.30632 \times 10^{-1}$ & 4 & $3.95532 \times 10^{0}$ & $3.95023 \times 10^{0}$ \\
5 & $6.61957 \times 10^{-1}$ & $6.61118 \times 10^{-1}$ & 5 & $4.47147 \times 10^{0}$ & $4.46693 \times 10^{0}$ \\
6 & $6.99601 \times 10^{-1}$ & $6.98869 \times 10^{-1}$ & 6 & $5.83890 \times 10^{0}$ & $5.76753 \times 10^{0}$ \\
7 & $1.07370 \times 10^{0}$ & $1.07308 \times 10^{0}$ & 7 & $7.91385 \times 10^{0}$ & $7.89320 \times 10^{0}$ \\
8 & $1.08798 \times 10^{0}$ & $1.08722 \times 10^{0}$ & 8 & $9.21933 \times 10^{0}$ & $9.20979 \times 10^{0}$ \\
9 & $1.68962 \times 10^{0}$ & $1.68661 \times 10^{0}$ & 9 & $1.01272 \times 10^{1}$ & $1.02861 \times 10^{1}$ \\
10 & $1.83475 \times 10^{0}$ & $1.83001 \times 10^{0}$ & 10 & $1.23857 \times 10^{1}$ & $1.24129 \times 10^{1}$ \\
\hline
\end{tabular}

